\title{
PENGARUH SUKU BUNGA, PER, DAN PBV TERHADAP HARGA SAHAM PERUSAHAAN SUB SEKTOR KONSTRUKSI BANGUNAN
}

\section{THE EFFECT OF INTEREST RATE, PER, AND PBV ON THE SHARE PRICE OF CONSTRUCTION SUB-SECTOR COMPANIES}

\author{
Rosa Arbaningrum ${ }^{1}$, Asep Muslihat ${ }^{2}$ \\ Universitas Singaperbangsa Karawang, Indonesia ${ }^{1,2}$ \\ rosaabaningrum25@gmail.com ${ }^{1}$
}

\begin{abstract}
The study aims to determine how much influence of interest rate, PER, and PBV have on stock prices. The method used is descriptive verification with a quantitative approaches. Data were analyzed using multiple linear regression analysis. Based on the results of a descriptive analysis of the highest interest rate occurred in 2014-2015 while the lowest interest rate in the 2017. There are 5 building construction sub-sector companies that have PER industry average, while 4 other companies have PER above industry average. Furthermore, there are 4 companies that have the value of $P B V$ below the industry average and 5 companies have $P B V$ above the industry average. Then, there are 5 companies that have a share price above the industry average and 4 companies have the stock price below the industry average. Based on the result of verificative analysis that interest rate variable has no signification effect on stock price, while PER variable has no signification effect on stock price and PBV variable has signification effect on stock price. $R$ square test result show that the interest rate, $P E R$, and PBV has effect of 29,3\% against the stock price so that remaining $71,7 \%$ is affected by other variables that are not researched.
\end{abstract}

Keywords: Interest Rate; PER; PBV; Stock Price.

\begin{abstract}
ABSTRAK
Penelitian ini bertujuan untuk mengetahui sebarapa besar pengaruh Suku Bunga, PER, dan PBV terhadap harga saham. Metode yang digunakan adalah deskriptif verifikatif dengan pendekatan kuantitatif. Data dianalisis dengan menggunakan analisis regresi linier berganda. Berdasarkan hasil analisis deskriptif suku bunga tertinggi terjadi pada tahun 2014-2015 sedangkan suku bunga terendah terjadi pada tahun 2017. Terdapat 5 perusahaan sub sektor konstruksi bangunan yang memiliki PER dibawah rata-rata industri, sedangkan 4 perusahaan lainnya memiliki PER diatas rata-rata industri. Selanjutnya, terdapat 4 perusahaan yang memiliki nilai PBV dibawah rata-rata industri dan 5 perusahaan memiliki PBV diatas rata-rata industri. Kemudian, terdapat 5 perusahaan yang memiliki harga saham diatas rata-rata industri dan 4 perusahaan memiliki harga saham dibawah rata-rata industri. Berdasarkan hasil analisis menyatakan bahwa variabel suku bunga tidak berpengaruh signifikan terhadap harga saham, sementara PER berpengaruh tidak signifikan terhadap harga saham, dan PBV berpengaruh signifikan terhadap harga saham. Hasil pengujian R square menunjukkan suku bunga, PER dan PBV berpengaruh sebesar 29,3\% terhadap harga saham sehingga $71,7 \%$ sisanya dipengaruh oleh variabel lain yang tidak diteliti.
\end{abstract}

Kata Kunci: Suku Bunga; PER; PBV; Harga Saham. 


\section{PENDAHULUAN}

Pembangunan infrastruktur sangat diperlukan dalam suatu negara karena selain bertujuan meningkatkan perekonomian negara juga dapat meningkatkan kesejahteraan masyarakat. Infrastruktur akan menjadi investasi asset jangka panjang suatu negara. Maka dalam empat tahun yakni tahun 2015-2019, kabinet Jokowi-JK menjadikan pembangunan infrastruktur dalam salah satu program kerja prioritas. Dikutip dari kemenkeu.go.id, anggaran infrastruktur tahun 2014 sebesar Rp 155 triliun kemudian tahun 2018 meningkat menjadi Rp 410 triliun.

Pasar modal mempunyai peran yang strategis dalam pembangunan nasional sebagai salah satu sumber pembiayaan bagi dunia usaha dan wahana investasi bagi masyarakat (UU no 8 tahun 1995 pasal 1 ayat 13). Salah satu instrumet pasar modal yang paling terkenal adalah saham. Saham merupakan bentuk kepemilikan suatu perusahaan yang dapat diperjual belikan (Hartono, 2017). Harga saham yang selalu berubah-ubah dapat menjadi daya tarik bagi investor. Sehingga sebelum memutuskan untuk membeli saham perusahaan, seorang investor harus mampu menganalisis agar nantinya mendapatkan keuntungan (capital gain) dari investasi tersebut.

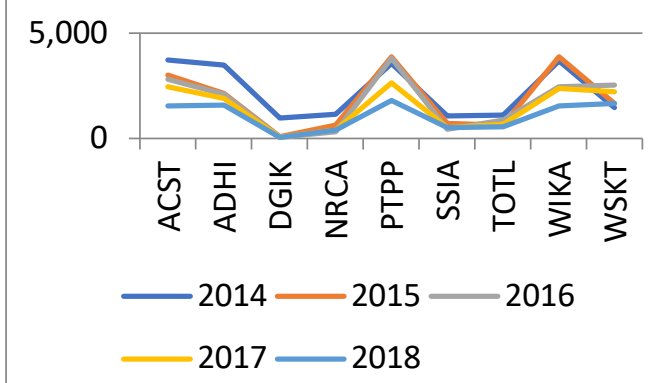

Sumber: www.idx.co.id, 2020

Gambar 1 Grafik Harga Saham Perusahaan Sub Sektor Konstruksi Bangunan

Salah satu faktor yang mempengaruhi fluktuasi harga saham adalah kondisi makro ekonomi. Kondisi makro ekonomi sangat mempengaruhi besar kecilnya suku bunga. Menurut Tandelilin (2014), tingkat bunga yang tinggi akan meningkatkan biaya modal yang harus ditanggung perusahaan. Tingkat suku bunga yang tinggi juga merupakan sinyal negatif terhadap harga saham perusahaan.

Salah satu rasio yang digunakan dalam analisis saham secara fundamental adalah PER. Menurut Tandelilin (2014) mengindikasikan besarnya rupiah yang harus dibayarkan investor untuk memperoleh satu rupiah earning perusahaan. Selain Price Earning Ratio (PER) yang umum digunakan dalam analisis fundamental adalah Price Book Value (PBV). Brigham \& Gapenski (2006) dalam Latifatun (2017) Price Book Value (PBV) merupakan rasio keuangan yang menunjukkan hasil perbandingan antara harga pasar per lembar saham dengan nilai buku per lembar saham. Semakin tinggi Price Book Value (PBV) artinya pasar percaya dengan kinerja perusahaan.

\section{METODE PENELITIAN}

Metode penelitian yang digunakan adalah deskriptif kuantitatif karena peneliti perlu mengidentifikasi apakah data yang dimiliki memenuhi asumsi dasar yang harus dipenuhi setiap teknik dan tahapan awal dari penelitian yang selanjutkan data tersebut akan menggambarkan sebuah hasil dari penelitian

Variabel suku bunga (X1), Price Earning Ratio (X2), dan Price Book Value (PBV) sebagai variabel bebas dan harga saham (Y) sebagai variabel terikat.

Pengumpulan data dengan cara mengumpulkan dokumen atau arsip perusahaan baik data primer maupun data sekunder yang ada kaitannya 
dengan masalah yang akan dibahas yaitu berupa laporan keuangan perusahaan sub sektor konstruksi yang terdaftar di Bursa Efek Indonesia (BEI) yang dimuat dalam www.idx.co.id.

Populasi dari penelitian ini adalah semua perusahaan konstruksi yang terdaftar di Bursa Efek Indonesia yaitu sebanyak 18 perusahaan. Penentuan sampel pada penelitian ini adalah menggunakan metode purpose sampling, dengan Jumlah perusahaan yang memenuhi kriteria yang telah di tentukan sebanyak 12 perusahaan.

\section{HASIL DAN PEMBAHASAN}

Berikut merupakan hasil pengolahan pengaruh Suku Bunga, PER, dan PBV terhadap Harga Saham

Tabel 1 Pengaruh Suku Bunga $\left(X_{1}\right)$ Terhadap Harga Saham (Y)

\begin{tabular}{|c|c|c|c|c|c|}
\hline \multicolumn{5}{|c|}{ Harga Saham (Y) } & \multirow[b]{2}{*}{ Kesimpulan } \\
\hline & Sig & $\alpha$ & $\begin{array}{l}\mathrm{T} \\
\text { hitung }\end{array}$ & $\begin{array}{l}\mathrm{T} \\
\text { tabel }\end{array}$ & \\
\hline Pyx 1 & 0,879 & 0,05 & 0,154 & 2,009 & $\mathrm{H}_{0}$ diterima \\
\hline
\end{tabular}

Berdasarkan tabel 1 menunjukkan nilai sig $(0,879)>(0,05)$ dan $t$ hitung $(0,154)<(2,009)$ maka $\mathrm{H}_{0}$ diterima.

Tabel 2 Pengaruh PER $\left(\mathrm{X}_{2}\right)$ Terhadap Harga Saham (Y)

\begin{tabular}{llllll}
\multicolumn{6}{c}{ Saham (Y) } \\
\hline Sig & $\alpha$ & $\begin{array}{l}\mathrm{T} \\
\text { hitung }\end{array}$ & $\begin{array}{l}\mathrm{T} \\
\text { tabel }\end{array}$ & Kesimpulan \\
\hline Pyx $_{2}$ & 0,029 & 0,05 & - & 2,009 & $\mathrm{H}_{0}$ ditolak \\
& & & 2,255 & & \\
\hline
\end{tabular}

Sumber : Hasil pengolahan data SPSS 22

Berdasarkan tabel 2 menunjukkan nilai sig $(0,029)<(0,05)$ dan thitung $(-2,255)<(2,009)$ maka $\mathrm{H}_{0}$ ditolak.

Tabel 3 Pengaruh PBV $\left(X_{3}\right)$ Terhadap Harga

\begin{tabular}{llllll}
\multicolumn{6}{c}{ Saham (Y) } \\
\hline \multicolumn{1}{c}{ Sig } & $\alpha$ & $\begin{array}{l}\mathrm{T} \\
\text { hitung }\end{array}$ & $\begin{array}{l}\mathrm{T} \\
\text { tabel }\end{array}$ & Kesimpulan \\
\hline Pyx $_{3}$ & 0,001 & 0,05 & 3,623 & 2,009 & $\mathrm{H}_{0}$ ditolak \\
\hline
\end{tabular}

Sumber : Hasil pengolahan data SPSS 22
Berdasarkan tabel 3 menunjukkan nilai sig $(0,001)<(0,05)$ dan $t$ hitung $(3,623)$ $<(2,009)$ maka $\mathrm{H}_{0}$ ditolak.

Tabel 4 Pengaruh Simultan Suku Bunga $\left(X_{1}\right)$, PER $\left(X_{2}\right)$ dan PBV $\left(X_{3}\right)$ Terhadap Harga Saham (Y)

\begin{tabular}{llllll}
\hline & Sig & $\alpha$ & $\begin{array}{l}\mathrm{F} \\
\text { hitung }\end{array}$ & $\begin{array}{l}\mathrm{F} \\
\text { tabel }\end{array}$ & Kesimpulan \\
\hline Pyx & 0,000 & 0,05 & 8,191 & 2,78 & $\mathrm{H}_{0}$ ditolak \\
\hline
\end{tabular}

Sumber : Hasil pengolahan data SPSS 22

Berdasarkan tabel 4 menunjukkan nilai sig $(0,000)<(0,05)$ dan $\mathrm{t}$ hitung $\left(8,191>(2,78)\right.$ maka $\mathrm{H}_{0}$ ditolak.

\section{Pengaruh Suku Bunga terhadap Harga Saham}

Hasil penelitian menunjukkan, apabila terjadi kenaikan variabel suku bunga sebesar satu persen maka variabel harga saham akan mengalami kenaikan sebesar 1,817 persen atau menjadi 1,914 persen. Variabel suku bunga dalam mempengaruhi variabel harga saham sebesar $4,7 \%$, sedangkan $95,3 \%$ sisanya dipengaruhi oleh variabel lain yang tidak diteliti. Penelitian ini menunjukan bahwa $\mathrm{H}_{0}$ diterima, yang berarti suku bunga tidak berpengaruh terhadap harga saham

Sesuai dengan penelirian yang dilakukan dengan penelitian Tana (2017) yang hasilnya menunjukkan bahwa suku bunga tidak berpengaruh signifikan terhadap harga saham. Berbeda dengan Penelitian yang dilakukan oleh Andriyani \& Crystha (2016) dengan hasil penelitian bahwa suku bunga secara parsial berpengaruh signifikan terhadap harga saham,

\section{Pengaruh PER terhadap Harga Saham}

Hasil penelitian menunjukkan, apabila terjadi kenaikan variabel Price Earning Ratio sebesar satu kali maka variabel harga saham akan mengalami 
penurunan sebesar $-0,004$ kali atau menjadi 1,813 kali. Variabel Price Earning Ratio dalam mempengaruhi variabel harga saham sebesar $6 \%$, sedangkan $94 \%$ sisanya dipengaruhi oleh variabel lain yang tidak diteliti. Penelitian ini menujukan PER berpengaruh negative terhdap harga saham

Berbedaa dengan penelitian yang dilakukan oleh Astuti, et.al. (2018) dengan hasil penelitian bahwa Price Earning Ratio (PER) secara parsial berpengaruh positif terhadap harga saham dan Rian (2016) yang hasilnya menunjukkan bahwa Price Earning Ratio (PER) tidak berpengaruh terhadap harga saham.

\section{Pengaruh PBV terhadap Harga Saham}

Hasil penelitian menunjukkan apabila terjadi kenaikan variabel Price Book Value sebesar satu kali maka variabel harga saham akan mengalami kenaikan sebesar 0,247 kali atau menjadi 2,064 kali. variabel Price Book Value dalam mempengaruhi variabel harga saham sebesar $25 \%$, sedangkan $25 \%$ sisanya dipengaruhi oleh variabel lain yang tidak diteliti. Peneliti mengumukakan bahwa PBV berpengaruh terhadap harga saham

Penelitian ini menunjukan kesamaan seperti yang dilakukan Hanifah (2019) dan penelitian Bode (2019) yang hasilnya menunjukkan bahwa Price Book Value (PBV) berpengaruh terhadap harga saham.

\section{Pengaruh Suku Bunga, PER, dan PBV terhadap Harga Saham}

Hasil penelitian menunjukkan bahwa variabel bebas secara bersamasama yaitu suku bunga, Price Earning Ratio (PER) dan Price Book Value (PBV) mempengaruhi perubahan harga saham sebesar 29,3\%. Sementara sisanya $71,7 \%$ dijelaskan oleh variabel lain diluar persamaan regresi berganda atau yang tidak diteliti pada penelitian ini.

\section{PENUTUP}

\section{Kesimpulan}

Berdasarkan hasil penelitian dan pembahasan pada bab sebelumnya, dapat di kemukakan beberapa kesimpulan sebagai berikut.

1. Suku bunga pada perusahaan sub sektor konstruksi bangunan tertinggi terjadi pada tahun 2014 sampai dengan tahun 2015 yaitu sebesar 7,50\% sedangkan suku bunga terendah terjadi pada tahun 2017 sebesar $4,75 \%$.

2. Terdapat 5 perusahaan sub sektor konstruksi bangunan tahun 20142019 yang memiliki nilai PERdibawah rata-rata industri dan terdapat 4 perusahaan sub sektor konstruksi bangunan yang memiliki nilai rata-rata PER diatas rata-rata industri.

3. Terdapat 4 perusahaan sub sektor konstruksi bangunan tahun 20142019 yang memiliki nilai rata-rata PBV nilai rata-rata industri dan terdapat 5 perusahaan sub sektor konstruksi bangunan yang memilliki nilai rata-rata PBV diatas rata-rata industri.

4. Terdapat 5 perusahaan sub sektor konstruksi bangunan tahun 20142019 yang memiliki harga saham diatas rata-rata industri dan terdapat 4 perusahaan sub sektor konstruksi bangunan yang memilliki harga saham dibawah rata-rata industri.

5. Suku bunga tidak berpengaruh signifikan terhadap harga saham pada perusahaan sub sektor konstruksi bangunan yang terdaftar di Bursa Efek Indonesia Tahun 2014-2019. 
6. PER berpengaruh tidak signifikan terhadap harga saham pada perusahaan sub sektor konstruksi bangunan yang terdaftar di Bursa Efek Indonesia Tahun 2014-2019.

7. PBV berpengaruh signifikan terhadap harga saham pada perusahaan sub sektor konstruksi bangunan yang terdaftar di Bursa Efek Indonesia Tahun 2014-2019.

8. Suku Bunga, PER dan PBV berpengaruh signifikan terhadap harga saham pada perusahaan sub sektor konstruksi bangunan yang terdaftar di Bursa Efek Indonesia Tahun 2014-2019.

\section{Saran}

$\begin{array}{ccc}\text { Bagi } & \text { perusahaan sub } & \text { sektor } \\ \text { konstruksi } & \text { bangunan } & \text { untuk }\end{array}$ memperhatikan pembiayaan modal yang berasal dari utang, karena semakin tingginya pembiayaan modal yang berasal dari utang akan menambah beban bunga dan akan mempengaruhi laba perusahaan. Bagi 5 perusahaan yang memiliki nilai rata-rata PER dibawah rata-rata industri sebaiknya memperhatikan nilai PER dengan cara menaikkan harga pasar atau nilai pasar diatas laba perlembar saham. Bagi 4 perusahaan yang memiliki nilai rata-rata PBV dibawah rata-rata industri sebaiknya menaikkan nilai PBV dengan cara meningkatkan modal perusahaan diatas laba jumlah saham yang beredar.

Peneliti selanjutnya diharapkan menambah ataupun menggunakan faktor-faktor lainnya yang berkemungkinan mempengaruhi harga saham selain suku bunga, PER dan PBV. Peneliti selanjutnya sebaiknya menambah tahun penelitian agar hasil yang diperoleh mempunyai cakupan yang lebih luas sehingga akan memperoleh hasil yang lebih akurat.

\section{DAFTAR PUSTAKA}

Andriyani, I. \& Crystha, A. (2016). Pengaruh Suku Bunga, Inflasi, Nilai Buku terhadap Harga Saham Perusahaan Indeks LQ-45 yang Terdaftar di Bursa Efek Indonesia (BEI). Jurnal Ilmiah Orasi Bisnis 5(15):2085-1375

Astuti, P. Yunita, L., S \& Armalia, R, W. A. (2018). Analisis Pengaruh Return On Equity, Earning Per Share, Price to Book Value, Book Value Per Share, Price Earning Ratio dan Kepemilikan Institusional terhadap Harga Saham Perusahaan. Jurnal Ekonomi 20(2):170-83.

Bode, V. Fair. S. (2017). Analisis Pengaruh Nilai Pasar, Solvabilitas, dan Profitabilitas terhadap Harga Saham pada Perusahaan yang Terdaftar di Indeks LQ-45 Tahun 2013.

Brigham, E. F. \& Houston, F. J. (2011). Dasar-Dasar Manajemen Keuangan Edisi 10 (Bahasa Indonesia ed.). (A. Y. Akbar, Penerj.) Jakarta: Salemba Empat.

Hartono, J. (2017). Teori Portofolio Dan Analisis Investasi (11 ed.). Yogyakarta: BPFE.

Hanifah, A. (2019). The Effect of Earning Per Share (EPS), Price Earning Ratio (PER) and Price Book Value (PBV) Against the Stock Price of Telecommunications Sector Company Included in the Indonesian Islamic Stock Index (ISSI). KnE Social Sciences 2019:711-26.

IDX. (2020). Laporan Keuangan dan Tahunan" PT Bursa Efek Indonesia diakses 16 Februari 2020 dari https://www.idx.co.id/perusahaa n-tercatat/laporan-keuangan-dantahunan/. 
Latifatun, N. (2017). Price Earning Ratio (PER) Dan Price Book Value (PBV) Terhadap Return Saham dengan Earning Per Share (EPS) Sebagai Variabel Moderasi. Universitas Islam Negeri Maulana Malik Ibrahim Malang.

Rian, R. P. (2013). Analisis Pengaruh ROE, EPS, PBV, DER, dan NPM terhadap Harga Saham pada Perusahaan Real Estate dan Property di Bursa Efek Indonesia (Bei) Periode 2011 - 2013.

Tandelilin, E. (2014). Portofolio dan Investasi: Teori dan Aplikasi Edisi Kelima. Yogyakarta: Kanisius.

Tana, P., A. (2017). Pengaruh Suku Bunga, Nilai Tukar, Profitabilitas, Likuitas dan Solvabilitas terhadap Harga Saham pada Perusahaan BUMN yang Terdaftar di Bursa Efek Indonesia (BEI) Tahun 20132015. Fakultas Ekonomi Universitas Pakuan. 